\title{
Biodiesel Production from Fat of Tra Catfish via Heterogeneous Basic-Catalyzed Transesterification Using Ultrasonic Mixing*
}

\author{
Le Thi Thanh Huong ${ }^{\dagger}$ \\ Center of Chemical Industry, Ho Chi Minh City University of Industry, Ho Chi Minh City, Vietnam \\ Phan Minh Tan \\ Department of Science and Technology, Ho Chi Minh City, Vietnam \\ Tran Thi Viet Hoa \\ Faculty of Chemical Engineering, Ho Chi Minh City University of Technique, Ho Chi Minh City, Vietnam
}

(Received 13 November 2009; Accepted 29 June 2010; Published 27 December 2011)

\begin{abstract}
Biodiesel, an alternative diesel fuel, is made from renewable biological sources such as vegetable oil, waste cooking oil, and animal fat. This work for the first time presents the biodiesel production from Tra fat with methanol using $\mathrm{KOH} / \gamma-\mathrm{Al}_{2} \mathrm{O}_{3}$ catalyst as heterogeneous catalyst using low frequency ultrasonic mixing $(20 \mathrm{kHz})$. The main object of this study was to investigate the influences of parameters like methanol/fat molar ratio, catalyst concentration, time and temperature of reaction, wave amplitudes, and energy input on the yield of biodiesel. Moreover, this research also examined the influences of ultrasonic wave on the fatty acid composition and the properties of $\mathrm{KOH} / \gamma-\mathrm{Al}_{2} \mathrm{O}_{3}$ catalyst. [DOI: 10.1380/ejssnt.2011.477]
\end{abstract}

Keywords: Transesterification; Tra fat; Biodiesel; Heterogeneous catalyst; Ultrasonic

\section{INTRODUCTION}

Biodiesel, an alternative diesel fuel, is made from renewable biological sources such as vegetable oil, waste cooking oil, and animal fat. The most common method used to produce biodiesel is the transesterification with an alcohol (alcoholysis), most commonly, methanol (methanolysis), using sodium or potassium hydroxide as homogeneous catalysts or solid basic catalysts [1-5]. In this conventional method, triglycerides found in the oil and methanol are not completely miscible. The transesterification reaction only occurs in the interfacial region between the liquids, so thus, is a very slow process. As a result, a vigorous mixing is required to increase the area of contact between the two immiscible phases and thus, to produce an emulsion [6]. Recently, low frequency ultrasonic irradiation $(28-40 \mathrm{kHz})$, a useful tool for emulsification of immiscible liquids, is applied for research of biodiesel production.

Literature has reported the effects of ultrasonic mixing on the transesterification for biodiesel production $[7,8]$. Generally, it was reported that ultrasonic mixing had a significant effect of reducing the time of the transesterification. However, only few articles have mentioned the operating parameters of the ultrasonic processor such as ultrasonic amplitude, pulse, the geometrical arrangement of the horn in the irradiated medium, and energy input.

The fat of Tra and Basa catfish (Mekong Delta, Viet Nam) was evaluated as the potential feedstock for biodiesel production, due to its abundance, availability and cheap cost. The unsaturated fatty acid contents of Tra and Basa fat were $57.97 \%$ and $64.17 \%$, respectively. Biodiesel was prepared from Tra and Basa fat by

\footnotetext{
* This paper was presented at the International Workshop on Advanced Materials and Nanotechnology 2009 (IWAMN2009), Hanoi University of Science, VNU, Hanoi, Vietnam, 24-25 November, 2009 ${ }^{\dagger}$ Corresponding author: huong. lethanh@gmail.com
}

methanolysis reaction using $\mathrm{NaOH}$ and $\mathrm{KOH}$ catalysts. The type and quantity of catalyst, molar ratio of methanol to fat, the reaction temperature and reaction time were the main factors affecting the transesterification reaction. The biodiesel yields achieve more than 90\% under moderate conditions $([9])$.

This work presents the study of the methanolysis from Tra fat in the presence of $\mathrm{KOH} / \gamma-\mathrm{Al}_{2} \mathrm{O}_{3}$ catalyst as a heterogeneous catalyst using low frequency ultrasonic (20 $\mathrm{kHz}$ ). Besides above mentioned transesterification conditions, the effects of parameters of the ultrasonic processor such as ultrasonic amplitude and ultrasonic energy were investigated. Moreover, this research also examined the influences of ultrasonic wave on the fatty acid composition and the properties of $\mathrm{KOH} / \gamma-\mathrm{Al}_{2} \mathrm{O}_{3}$ catalyst.

\section{EXPERIMENTAL}

\section{A. Materials and equipment}

Tra fat was supplied from An Giang Agriculture and Food Export Company (Afiex). The commercial methanol $(90 \%)$ was commercially obtained. Potassium hydroxide $(86 \%)$ and aluminum hydroxide $(92 \%)$ were obtained from China. Standards and internal standards for quantitative analysis of methylesters were purchased from Fluka, United Kingdom. Chemicals used for analysis were purchased from Merck, Germany. The ultrasonic reactions were performed using Sonics Ultrasonic Processor VC 750. The processor operated at $750 \mathrm{~W}$ and $20 \mathrm{kHz}$ frequency and equipped as Fig. 1. The titanium alloy horn with tip diameter of $13 \mathrm{~mm}$ and a length of $136 \mathrm{~mm}$ is used to transmit the ultrasound into the liquid. Biodiesel product was dried by household microwave oven SANYO Fan-Assisted 1200W. 


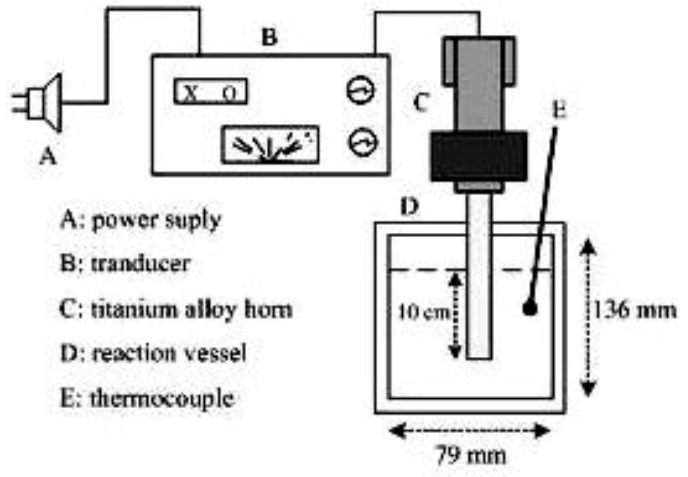

FIG. 1: The ultrasonic processor for the transesterification from Tra fat.

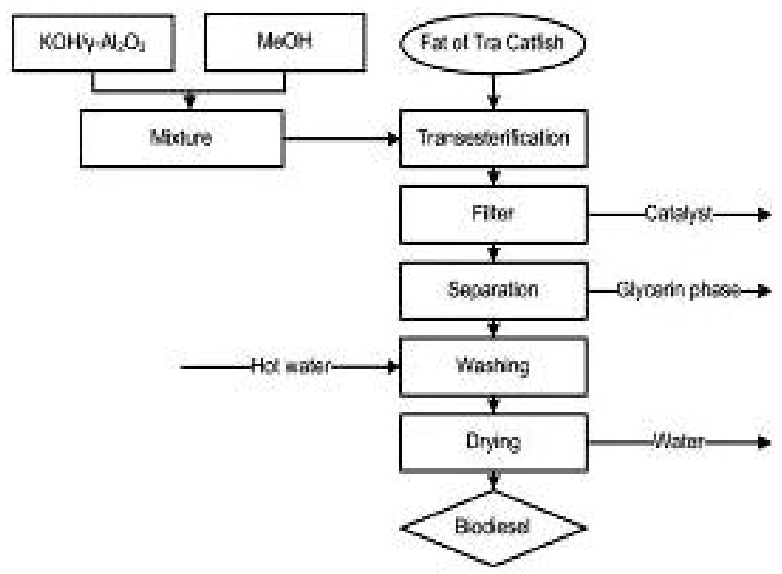

FIG. 2: Schematic of the transesterification from Tra fat.

\section{B. Experimental procedures}

\section{Catalyst preparation}

The $\gamma-\mathrm{Al}_{2} \mathrm{O}_{3}$ used as a support was obtained from the calcinations of the commercial hydroxide alumina $\mathrm{Al}(\mathrm{OH})_{3}$ for $6 \mathrm{~h}$ at $600-650^{\circ} \mathrm{C}$. A KOH $/ \gamma-\mathrm{Al}_{2} \mathrm{O}_{3}$ catalyst was prepared using the wet impregnation method with an aqueous solution of $\mathrm{KOH}$. The $\mathrm{KOH} / \gamma-\mathrm{Al}_{2} \mathrm{O}_{3}$ ratio was $7 \mathrm{mmol} / \mathrm{g}$. A required $\mathrm{KOH}$ amount was completely dissolved in distilled water at the room temperature. The support was then slowly added into the solution followed by vigorous mixing for $3 \mathrm{~h}$. After impregnation, the paste was dried in an oven for $12 \mathrm{~h}$ at $120^{\circ} \mathrm{C}$. Prior to the reaction, the dried catalyst was calcined in air for $2.5 \mathrm{~h}$ and at $550^{\circ} \mathrm{C}$.

The basic strength $\left(H_{-}\right)$of the prepared and collected catalyst (before and after transesterification reaction) was determined by using Hammett indicator [10]. The X-ray diffraction (XRD) of these catalysts were performed on a Siemen $\mathrm{D}-5000$ using the $\mathrm{Cu}-\mathrm{K} \alpha$ radiation, over a $2 \theta$ range of $20^{\circ}-74^{\circ}$ with a step size of $0,03^{\circ}$ at a scanning speed of $0.8^{\circ} / \mathrm{s}$. $\mathrm{KBr}$ pellet technique was applied for determining IR spectra of these catalysts. Spectra were recorded on a spectrometer with $4 \mathrm{~cm}^{-1}$ resolution by BRUCKER system.

\section{Transesterification}

The reaction system using ultrasonic processor and transesterification process from Tra fat with methanol using $\mathrm{KOH} / \gamma-\mathrm{Al}_{2} \mathrm{O}_{3}$ catalyst were performed according to Figure 1 and Fig. 2. The sonotrode was submerged up to $10 \mathrm{~cm}$ into the solution. The pulse time was kept constant at 5:5 (sec) for all experiments. The process parameters such as amplitude and operating time were set up. The control system automatically recorded the actual energy input (ultrasonic energy) and resultant temperature variation. Subsequently, biodiesel phase was washed three times by hot distilled water and was dried by microwave oven for $10 \mathrm{~min}$ at $380 \mathrm{~W}$. Parameters effecting the transesterification reaction such as methanol/fat molar ratio, catalyst concentration, time and temperature of reaction, ultrasonic amplitude, and ultrasonic energy were also investigated. The catalyst contain (wt \%) was calculated from the total weight of fat plus methanol prior to reaction. The transesterification reaction was carried out with conventional stirring heating (6/1 methanol/fat molar ratio, $0.8 \% \mathrm{KOH}$, at $50^{\circ} \mathrm{C}$ for $45 \mathrm{~min}$ ) to allow comparison with ultrasonic effects. The phase-separated time of the biodiesel phase and the glycerin phase were $2 \mathrm{~h}$ and $4 \mathrm{~h}$ for ultrasonic mixing and mechanical stirring reaction, respectively.

\section{Analysis}

Physicochemical properties of biodiesel were determined using standard test methods according to ASTM D 6751. Methylester content $C(\%)$ of biodiesel product was analyzed by FID gas chromatograph (HP 6890) equipped with HP INNOWAX column $(30 \mathrm{~m} \times 530 \mu \mathrm{m}$ $\times 1 \mu \mathrm{m})$ using helium as carrier gas. The solvent used was heptane. The split ratio was 50:1. Methyl hexanoate was used as the internal standard. The temperature program was started at $120^{\circ} \mathrm{C}$ and held 2 min, up to $230^{\circ} \mathrm{C}$ $\left(7^{\circ} \mathrm{C} / \mathrm{min}\right)$ and held $15 \mathrm{~min}$.

The production yield $(\mathrm{H})$ :

$$
H(\%)=\frac{m_{\text {biodiesel }} C}{\frac{3 m}{M} M_{F A M E}} \times 100
$$

where $m_{\text {biodiesel }}$ is amount of biodiesel product, $m$ amount of Tra fat, and $M$ and $M_{F A M E}$ average amount of a FAME molecular and Tra fat molecular.

\section{RESULTS AND DISCUSSIONS}

\section{A. Effect of molar ratio of methanol to fat}

The fixed factors in this study were $5 \%$ $\mathrm{KOH} / \gamma-\mathrm{Al}_{2} \mathrm{O}_{3}$ catalyst, 15 min reaction time, and $80 \%$ amplitude. Methanol/fat molar ratios were investigated from $10 / 1$ to $14 / 1$. The effect of methanol/fat molar ratio on the biodiesel yield of transesterifiaction reaction is shown in Fig. 3. There is an increase in the yield of conversion when the methanol/fat molar ratio is increased from $10 / 1$ to $11 / 1$. The maximum yield achieves $91.66 \%$ with $12 / 1$ molar ratio of methanol to fat. 


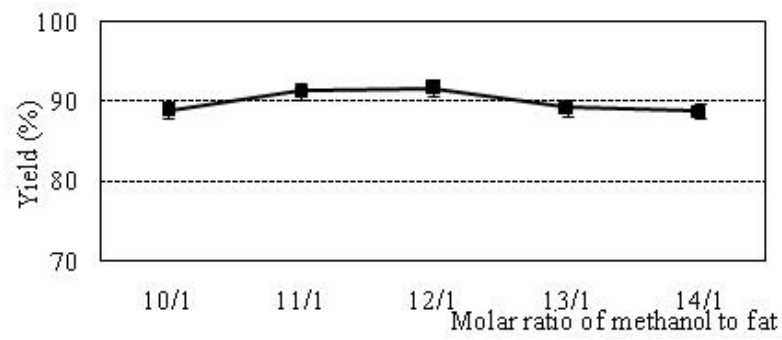

FIG. 3: Effect of methanol/fat molar ratio on the biodiesel yield.

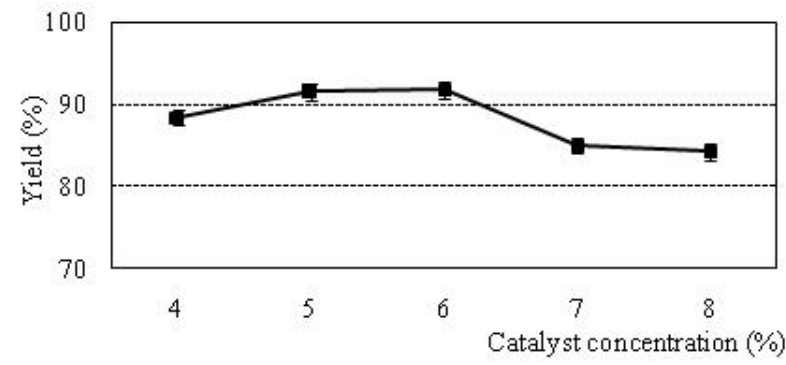

FIG. 4: Effect of catalyst concentration on the biodiesel yield.

Theoretically, the required methanol/triglyceride molar ratio is $3 / 1$. However, because of a reversible reaction, excess of alcohol is required in order to shift the equilibrium of reaction to the product side. Increases in methanol/fat molar ratio (higher than 12/1) do not increase the yield of conversion, and the separating and washing steps of biodiesel from glycerin become even more difficult due to the formation emulsion of excessive methanol with glycerin phase. Hence, 12/1 molar ratio of methanol to fat is the optimal ratio for the transesterifiaction with the ultrasonic mixing.

\section{B. Effect of catalyst concentration}

The fixed factors were $12 / 1$ molar ratio of methanol to fat, $15 \mathrm{~min}$ reaction time, and $80 \%$ amplitude. Investigated concentration of catalyst was from 5 to $8 \%$. The results shown in Fig. 4 indicate that the yield of biodiesel increases from 91.66 to $91.8 \%$ when $\mathrm{KOH} / \gamma-\mathrm{Al}_{2} \mathrm{O}_{3}$ concentration is increased from 5 to $6 \%$.

Then the yield decreases when $\mathrm{KOH} / \gamma-\mathrm{Al}_{2} \mathrm{O}_{3}$ concentrations are higher than $6 \%$ because the density increasing of reaction mixing could reduce the interactive ability of reactants. In short, the best concentration of $\mathrm{KOH} / \gamma-\mathrm{Al}_{2} \mathrm{O}_{3}$ catalyst for the transesterification is $6 \%$ and the maximum yield of biodiesel is $91.8 \%$.

\section{Effect of ultrasonic amplitude and reaction time}

The amplitude of ultrasonic and the reaction time have significant effects on the transesterification reaction. To better describe these results, data on ultrasonic energy, temperature, and yield of the biodiesel under the above optimized conditions $(12 / 1$ molar ratio of methanol/fat, $\left.6 \% \mathrm{KOH} / \gamma-\mathrm{Al}_{2} \mathrm{O}_{3}\right)$ are shown in Table I. It finds that the amplitude and the reaction time have effects on the
TABLE I: Effects of amplitude, reaction time, and ultrasonic energy on the biodiesel yield.

\begin{tabular}{ccccc}
\hline \hline Amplitude & $\begin{array}{c}\text { Reaction } \\
\text { time } \\
(\text { min })\end{array}$ & $\begin{array}{c}\text { The biodiesel } \\
\text { yield } \\
(\%)\end{array}$ & $\begin{array}{c}\text { Ultrasonic } \\
\text { energy } \\
(\mathrm{J})\end{array}$ & $\begin{array}{c}\text { Reaction } \\
\text { temperature } \\
\left({ }^{\circ} \mathrm{C}\right)\end{array}$ \\
\hline 70 & 5 & 87 & 15679 & 45 \\
80 & 5 & 89.1 & 20612 & 47 \\
90 & 5 & 91.2 & 25273 & 48 \\
100 & 5 & 91.3 & 29966 & 50 \\
70 & 10 & 90.4 & 37632 & 47 \\
80 & 10 & 90.5 & 49122 & 48 \\
90 & 10 & 90.1 & 62615 & 50 \\
100 & 10 & 89.6 & 71445 & 54 \\
70 & 15 & 90.8 & 49818 & 50 \\
80 & 15 & 91.8 & 79342 & 49 \\
90 & 15 & 89.4 & 89332 & 51 \\
100 & 15 & 87 & 95265 & 56 \\
70 & 20 & 92.3 & 79634 & 51 \\
80 & 20 & 90.4 & 102000 & 54 \\
90 & 20 & 86.6 & 139601 & 55 \\
100 & 20 & 81.7 & 141981 & 60 \\
\hline \hline
\end{tabular}

reaction temperature, especially on ultrasonic energy and biodiesel yield. The effect of amplitude and reaction time on ultrasonic energy is shown in Fig. 5.

It notices that the ultrasonic energy gets high as the high amplitude and the long reaction time. With the same level of amplitude, the longer reaction time results in the higher ultrasonic energy.
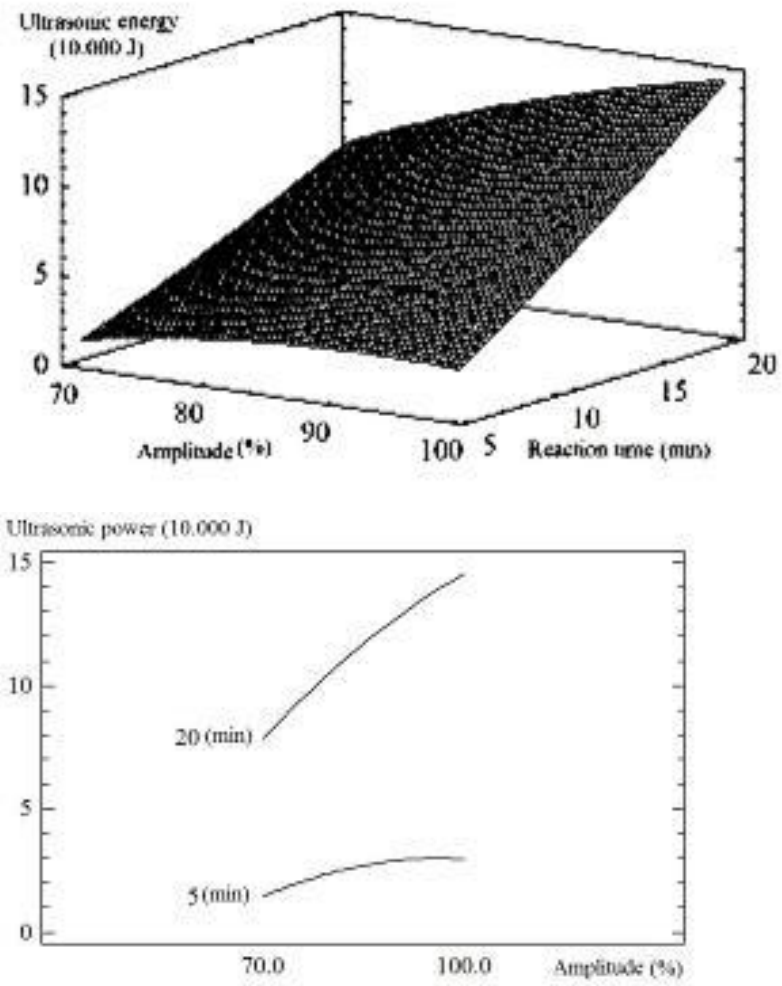

FIG. 5: Effects of amplitude and reaction time on ultrasonic energy. 


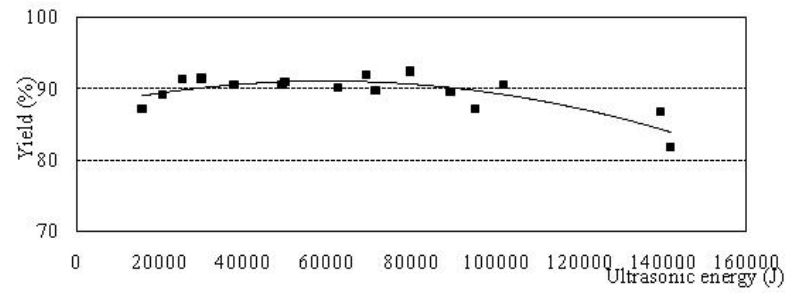

FIG. 6: Effects of ultrasonic energy on the biodiesel yield.

The relation between the ultrasonic energy and the biodiesel yield is shown in Fig. 6. It finds clearly that when the ultrasonic energy increases, the yield of biodiesel increases, and reaches to the maximum, and then starts to decline, mainly due to cracking and degradation. It observes that, in order to achieve biodiesel yields $>90 \%$, the range for ultrasonic energy should be maintained between 25000 and $81000 \mathrm{~J}$.

The effects of ultrasonic amplitude and reaction time on the biodiesel yield also are presented in Fig. 7. It finds that the biodiesel yield depends simultaneously on amplitude and reaction time. For short reaction times (5 min), increasing ultrasonic amplitude results in continuous increases in the yield. However, with longer reaction times such as 15 and $20 \mathrm{~min}$, the high yields only achieve at the low amplitude.

At $70 \%$ amplitude, the longer reaction time results in the higher biodiesel yield. Increasing in amplitude from $80 \%$ to $100 \%$ for the long reaction time results in drastically decreases in the yields; particularly at $100 \%$ amplitude. The yield achieves the lowest $81.7 \%$ for $20 \mathrm{~min}$ reaction time. This could be explained by the cracking phenomenon that is followed by oxidation of FAME to aldehydes, ketones, and lower-chained organic fractions. The highest yield is $92.3 \%$ at $70 \%$ amplitude level for 20 min reaction time; and the corresponding ultrasonic energy and reaction temperature are $79634(\mathrm{~J})$ and $51^{\circ} \mathrm{C}$, respectively.

D. Effect of $\mathbf{K O H} / \gamma-\mathrm{Al}_{2} \mathrm{O}_{3}$ in a comparative perspective with $\mathrm{KOH}$ homogeneous catalyst using ultrasonic mixing and mechanical stirring

The results are shown in Table II. It notices that the ultrasonic mixing promotes the transesterification rate because the reaction time is reduced significantly, both with heterogeneous and homogeneous catalyst. For $\mathrm{KOH} / \gamma-\mathrm{Al}_{2} \mathrm{O}_{3}$ heterogeneous catalyst, it reduces to $77 \%$ reaction time and to $50 \%$ phase-separated time. Moreover, it observes that no soap is formed at the low amplitude from $70 \%$ to $80 \%$.

\section{E. Effect of ultrasonic on the activity of catalyst}

The basic strength of the collected catalyst is lower than that of the prepared catalyst $(3.37 \mathrm{mmol} / \mathrm{g}$ and $3.97 \mathrm{mmol} / \mathrm{g}$, respectively). The effect of ultrasonic on the activity of $\mathrm{KOH} / \gamma-\mathrm{Al}_{2} \mathrm{O}_{3}$ heterogeneous catalyst is also assessed by the IR and XRD characterization of prepared and collected catalysts (Figs. 8 and 9).
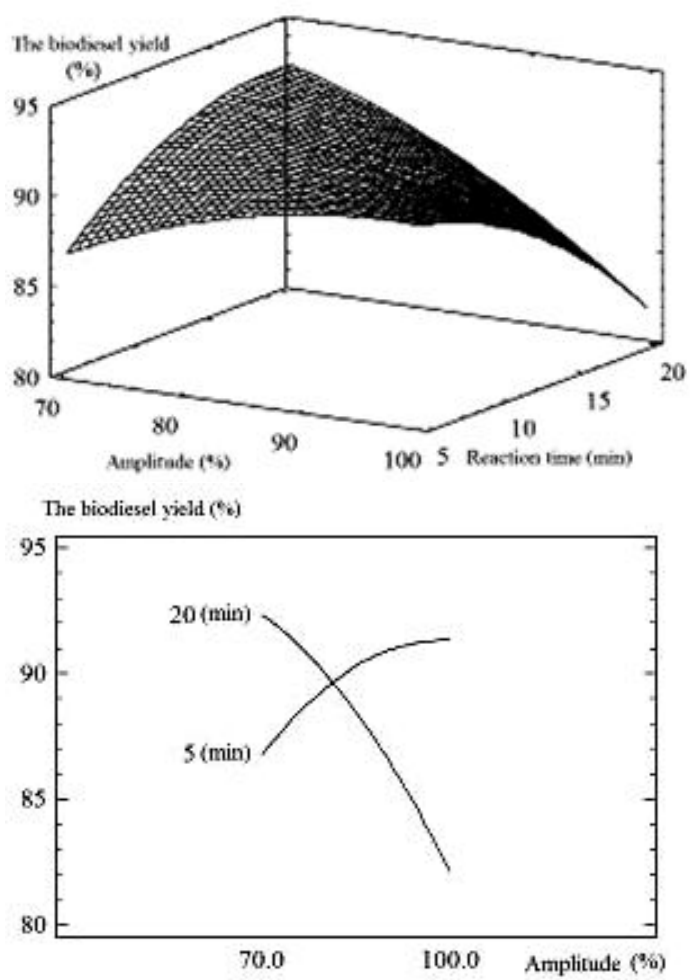

FIG. 7: Effect of amplitude and reaction time on the biodiesel yield.

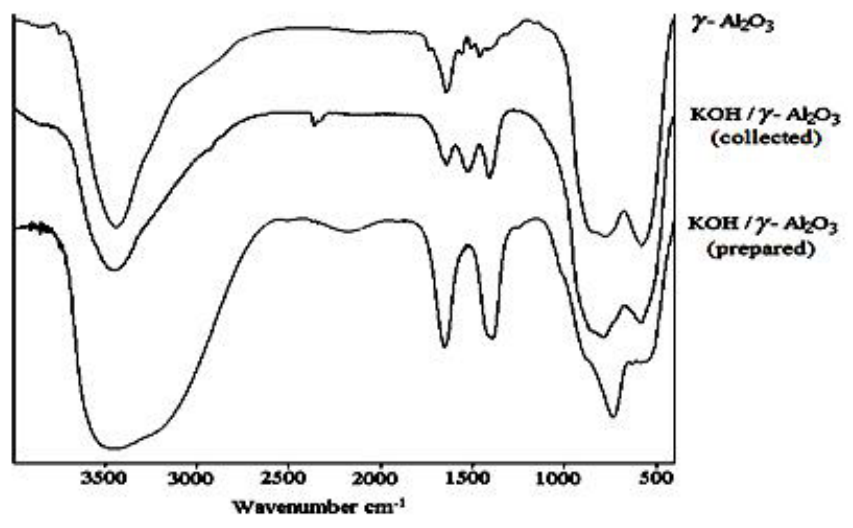

FIG. 8: IR spectra for $\gamma-\mathrm{Al}_{2} \mathrm{O}_{3}, \mathrm{KOH} / \gamma-\mathrm{Al}_{2} \mathrm{O}_{3}$ prepared and collected catalyst.

It finds the similar characterization of $\mathrm{KOH} / \gamma-\mathrm{Al}_{2} \mathrm{O}_{3}$ prepared and collected catalysts, but the later is at a lower level. In that way, the ultrasonic reduces the activity of the $\mathrm{KOH} / \gamma-\mathrm{Al}_{2} \mathrm{O}_{3}$ heterogeneous catalyst. However, after transesterification reaction, the collected $\mathrm{KOH} / \gamma-\mathrm{Al}_{2} \mathrm{O}_{3}$ catalyst could be refreshed by the loading additional $\mathrm{KOH}$ sodium hydroxide. Thus, the $\mathrm{KOH} / \gamma-\mathrm{Al}_{2} \mathrm{O}_{3}$ heterogeneous catalyst could be reused many times. It will be mentioned in our next work.

\section{F. Effect of ultrasonic on the properties of biodiesel}

Biodiesel products are light yellow, transparent liquids. Some of the important physicochemical properties of biodiesel such as viscosity $40^{\circ} \mathrm{C}(4.47)$, water content 
TABLE II: Effect of $\mathrm{KOH} / \gamma-\mathrm{Al}_{2} \mathrm{O}_{3}$ in a comparative perspective with $\mathrm{KOH}$ homogeneous catalyst using two methods.

\begin{tabular}{|c|c|c|c|c|}
\hline \multirow[t]{2}{*}{ Parameters } & \multicolumn{2}{|c|}{$\mathrm{KOH}$} & \multicolumn{2}{|c|}{$\mathrm{KOH} / \gamma-\mathrm{Al}_{2} \mathrm{O}_{3}$} \\
\hline & Mechanical stirring & Ultrasonic mixing & Mechanical stirring & Ultrasonic mixing \\
\hline Methanol/fat molar ratio & $6 / 1$ & $12 / 1$ & $8 / 1$ & $12 / 1$ \\
\hline Catalyst concentration (\%) & 0.8 & 0.8 & 6 & 6 \\
\hline Reaction time (min) & 45 & 20 & 90 & 20 \\
\hline Reaction temperature $\left({ }^{\circ} \mathrm{C}\right)$ & 50 & 47 & 60 & 51 \\
\hline Amplitude (\%) & & 70 & & 70 \\
\hline Ultrasonic energy $(\mathrm{J})$ & & 73248 & & 79634 \\
\hline The biodiesel yield (\%) & 92.7 & 92.7 & 92.6 & 92.3 \\
\hline
\end{tabular}

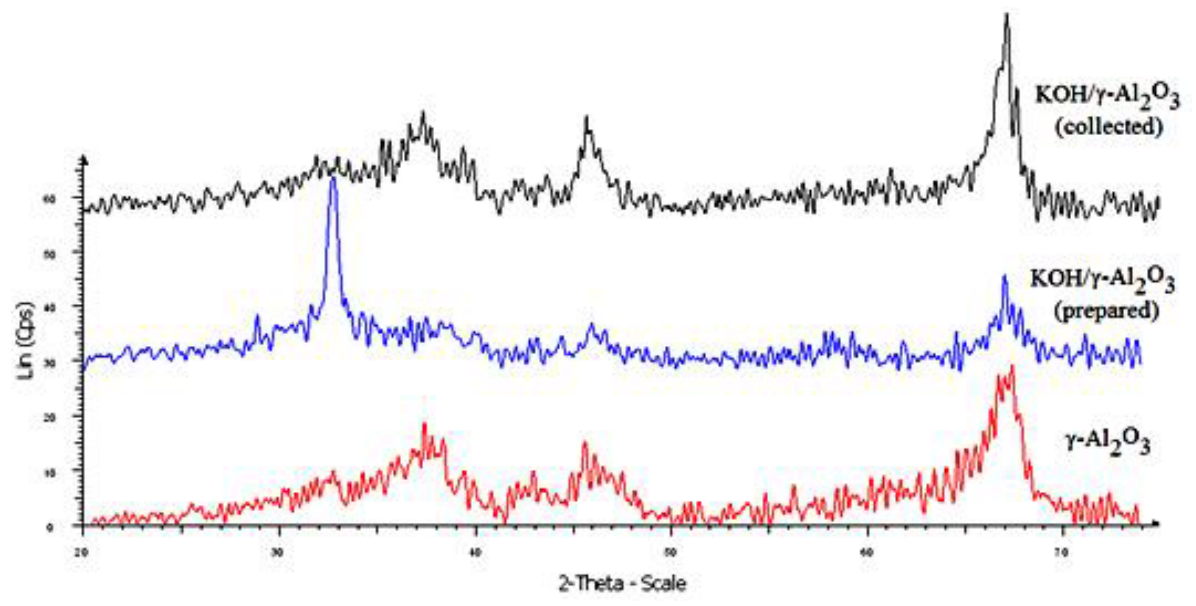

FIG. 9: XRD patterns for $\gamma-\mathrm{Al}_{2} \mathrm{O}_{3}, \mathrm{KOH} / \gamma-\mathrm{Al}_{2} \mathrm{O}_{3}$ prepared and collected catalyst.

(trace), acid value $(0.12 \mathrm{mg} \mathrm{KOH} / \mathrm{g})$, free glycerin $(0.0016$ $\% \mathrm{w} / \mathrm{w})$, and total glycerin $(0.018 \% \mathrm{w} / \mathrm{w})$ are similar under the optimum reaction condition in ultrasonic mixing and conventional mechanical stirring. In comparison with GC chromatograms of the biodiesel produced by conventional method, it finds that the fatty acid compositions are similar in the two mixing methods. Thus, ultrasonic heating and mixing have effect only on the acceleration of transesterification reaction and not on the chemical composition of biodiesel.

\section{CONCLUSIONS}

We can conclude that ultrasonic is an efficient, time saving and economically functional method to produce biodiesel from Tra fat. Ultrasonic heating and mixing have no effect on physicochemical properties and the fatty acid composition of biodiesel. The parameters which have effect on the biodiesel yield are methanol/fat molar ratio, catalyst concentration, time and temperature of transesterification reaction, amplitude level and ultrasonic energy. The high biodiesel yields would be obtained under the conditions of the short reaction time and the high amplitude level or the long reaction time and the low amplitude level. In comparison with the biodiesel production using the conventional method, ultrasonic heating and mixing also reduces $50 \%$ of the time of phase separation (from $4 \mathrm{~h}$ to $2 \mathrm{~h}$ ). However, the ultrasonic also reduces the activity of the $\mathrm{KOH} / \gamma-\mathrm{Al}_{2} \mathrm{O}_{3}$ heterogeneous catalyst.
[1] U. Schuchardt, R. Sercheli, and R. M. Vargas, J. Brazilian Chem. Soc. 9, 199 (1998).

[2] H. Fukuda, A. Kondo, and H. Noda, J. Biosci. Bioeng. 92, 405 (2001).

[3] J. Van Gerpen, B. Shanks, R. Pruszko, D. Clements, and G. Knothe, Report for the National Renewable Energy Laboratory. USA: Department of Energy, pp. 30-42 (2004).

[4] E. Lotero, J. G. Goodwin Jr, D. A. Bruce, K. Suwannakarn, Y. Liu, and D.E. Lopez, Catalysis 19, 41 (2006).

[5] H. Ma, S. Li, B. Wang, R. Wang, and S. Tian, J. Am. Oil Chem. Soc. 85, 263 (2008).
[6] O. S. Stamenkovic, M. L. Lazic, Z. B. Todorovic, V. B. Veljkovic, and D. U. Skala, Bioresource Technology 98, 2688 (2007).

[7] C. Stavarache, M. Vinatoru, Y. Maeda, and H. Bandow 14, 413 (2007).

[8] H. D. Hanh, et al., Renewable Energy 34, 780 (2009).

[9] L. T. T. Huong, P. M. Tan, T. T. V. Hoa, and S. Lee, J. Korean Oil Chem. Soc. 25, 418 (2008).

[10] W. Xie, H. Peng, and L. Chen, Appl. Catal. A 300, 67 (2006). 